\title{
Three-dimensional morphological study of the proximal femur in Crowe type IV developmental dysplasia of the hip
}

\author{
Yuhui Yang ${ }^{1 \dagger}$, Weihong Liao ${ }^{1 \dagger}$, Weiqun $\mathrm{Yi}^{2+}$, Hai Jiang ${ }^{1}$, Guangtao $\mathrm{Fu}^{1}$, Yuanchen Ma ${ }^{1 *}$ and Qiujian Zheng ${ }^{1 *}$
}

\begin{abstract}
Background: When performing femoral reconstruction in patients with Crowe type IV developmental dysplasia of the hip (DDH), anatomical deformity presents many technical challenges to orthopedic surgeons. The false acetabulum is suggested to influence load transmission and femoral development. The aim of this study was to describe the morphological features of dysplastic femurs in Crowe type IV DDH and further evaluate the potential effect of the false acetabulum on morphological features and medullary canal of Crowe type IV femurs.

Methods: We analyzed preoperative computed tomography scans from 45 patients with 51 hips (25 hips without false acetabulum in the IVa group and 26 hips with false acetabulum in the IVb group) who were diagnosed with Crowe type IV DDH and 30 normal hips in our hospital between January 2009 and January 2019. Three-dimensional reconstruction was performed using Mimics software, and the coronal femoral plane was determined to evaluate the following parameters: dislocation height, dislocation ratio, height of the femoral head (FH), height of the greater trochanter (GT), GT-FH height discrepancy, height of the isthmus, neck-shaft angle, femoral offset and anteversion of the femoral neck. The mediolateral (ML) width, anterolateral (AP) width and diameter of medullary canal of the proximal femur were measured on the axial sections. Further, canal flare index (CFI), metaphyseal-CFI and diaphyseal-CFI were also calculated.
\end{abstract}

Results: Compared with the normal femurs, the Crowe type IV DDH femurs had a higher femoral head, larger GT-FH height discrepancy, larger femoral neck anteversion, higher isthmus position and smaller femoral offset. Dislocation height and dislocation rate were significantly larger in the IVa DDH group ( $65.34 \pm 9.83 \mathrm{~mm}$ vs. $52.24 \pm 11.42 \mathrm{~mm}$ ). Further, the IVb femurs had a significantly lower isthmus position, larger neck-shaft angle and smaller femoral neck anteversion than IVa femurs. The ML, AP canal widths and the diameter of medullary canal in both DDH groups were significantly smaller than the normal group. Dimensional parameters of IVa femurs were also narrower than IVb femurs in most sections, but with no difference at the level of isthmus. According to the CFIs, the variation of proximal medullary canal in IVb femurs was mainly located in the diaphyseal region, while that in IVa femurs was located in the whole proximal femur.

\footnotetext{
*Correspondence: mayuanchen@gdph.org.cn; zhengqiujian@gdph.org.cn

tYuhui Yang, Weihong Liao and Weiqun Yi have contributed equally to

this work.

${ }^{1}$ Department of Orthopedics, Guangdong Provincial People's Hospital,

Guangdong Academy of Medical Sciences, 106, Zhongshan Second

Road, Yuexiu District, Guangzhou 510080, Guangdong Province, People's

Republic of China
}

Full list of author information is available at the end of the article original author(s) and the source, provide a link to the Creative Commons licence, and indicate if changes were made. The images or other third party material in this article are included in the article's Creative Commons licence, unless indicated otherwise in a credit line to the material. If material is not included in the article's Creative Commons licence and your intended use is not permitted by statutory regulation or exceeds the permitted use, you will need to obtain permission directly from the copyright holder. To view a copy of this licence, visit http://creativecommons.org/licenses/by/4.0/. The Creative Commons Public Domain Dedication waiver (http://creativeco mmons.org/publicdomain/zero/1.0/) applies to the data made available in this article, unless otherwise stated in a credit line to the data. 
Conclusions: High dislocated femurs are associated with more anteverted femoral neck, smaller femoral offset and narrower medullary canal. Without stimulation of the false acetabulum, IVa DDH femurs were associated with higher dislocation and notably narrower medullary canal, whose variation of medullary canal was located in the whole proximal femur.

Keywords: Developmental dysplasia of the hip, Crowe IV, Femoral morphology, Three-dimensional reconstruction, Total hip arthroplasty

\section{Introduction}

Developmental dysplasia of the hip (DDH) has been widely considered to be one of the most common causes of premature osteoarthritis and represents a spectrum of pathological abnormalities in the acetabular and femoral structures [1-3]. Total hip arthroplasty (THA) is considered to be an effective and standard treatment for patients with end-stage hip diseases. However, the severe deformity of hip dysplasia presents many technical challenges to orthopedic surgeons $[4,5]$. Compared with osteoarthritis, the increased femoral complications of THA in DDH patients are associated with pathoanatomical features of the femoral medullary canal, especially in high dislocated Crowe type IV DDH patients [6-8].

Due to the presence of a false acetabulum, the Crowe type IV DDH hips were divided into IVa (without false acetabulum) and IVb (with false acetabulum) [9, 10]. Zhou et al. [11] suggested that the presence of a false acetabulum is an important factor for determining dislocation height and subtrochanteric osteotomy application in THA. Hartofilakidis et al. $[6,12]$ revealed that long-term implant survival after THA was significantly worse in the high dislocation DDH patients without false acetabulum, which may be a result of the anatomical conditions in two subtypes. The presence of false acetabulum in high dislocation hip was suggested to play an important role in femoral development. The Dorr type of femoral medullary canal was also proved to be associated with periprosthetic femoral fracture in patients with DDH [7]. Thus, the morphological features of the femoral proximal medullary canal are of major concern for improving preoperative planning and avoiding perioperative complications in Crowe type IV DDH patients.

Compared with conventional 2-dimensional (2D) radiographs, 3-dimensional (3D) images are more effective in detecting the morphological features and in assessing the medullary shape of the dysplastic femurs [4, 13]. To our knowledge, few studies have addressed the morphology and proximal femoral anatomy of the dysplastic femur in type IV DDH. We hypothesize that there exist morphological abnormalities in Crowe type IV femurs, and the presence of false acetabulum can also influence femoral development and anatomic structures. In this study, we sought to compare (1) the 3D morphological features between normal and dysplastic femurs in Crowe type IV DDH and (2) the 3D femoral anatomy and medullary canal variation between IVa and IVb DDH femurs.

\section{Patients and methods Study subjects}

The study was approved by the institutional review board of Guangdong Provincial People's Hospital (IRB: 2019528HR1). We retrospectively reviewed the preoperative imaging data of 352 patients (496 hips) with DDH between January 2009 and January 2019. According to the Crowe classification, 52 patients (60 hips) were graded as type IV DDH on standing anteroposterior pelvic radiographs. The height of the dislocation was measured on standard AP plain radiographs and was defined as the vertical distance between the head-neck junction and the line connecting the lower edges of the bilateral teardrops. The exclusion criteria included (1) patients who underwent prior hip surgery; (2) patients with a dislocation attributed to infection or trauma; and (3) patients who did not have preoperative CT data or had substandard CT data. Thus, 51 dysplastic hips in 45 patients met the inclusion criteria and were retrospectively evaluated. The included patients were further divided as follows: group IVa, a dislocated femoral head located within the abductor muscle mass, and group IVb, evidence of the formation of a false acetabulum (Fig. 1). Herein, 25 hips were included in the IVa group and 26 hips were included in IVb group, with 3 patients affected by bilateral Crowe type IV DDH in each group. Fifteen patients (30 hips) without hip disease or deformities who had undergone computed tomography angiography (CTA) to diagnose vascular diseases were chosen as controls. Demographic data for the subjects are shown in Table 1.

\section{Image analysis and measurements}

Pelvic CT was performed with a Toshiba brand Aquilion CT scanner $(120 \mathrm{kVp}, 320 \mathrm{~mA}, 512 \times 512$ matrix; slice thickness $0.5 \mathrm{~mm}$ ) at the Guangdong Provincial People's Hospital. The patients were placed in a neutral supine position with the patellae facing the ceiling. Scanning was performed from the iliac crest to the complete femoral condyles. All standard CT slices were saved in digital imaging and communications in medicine (DICOM) 

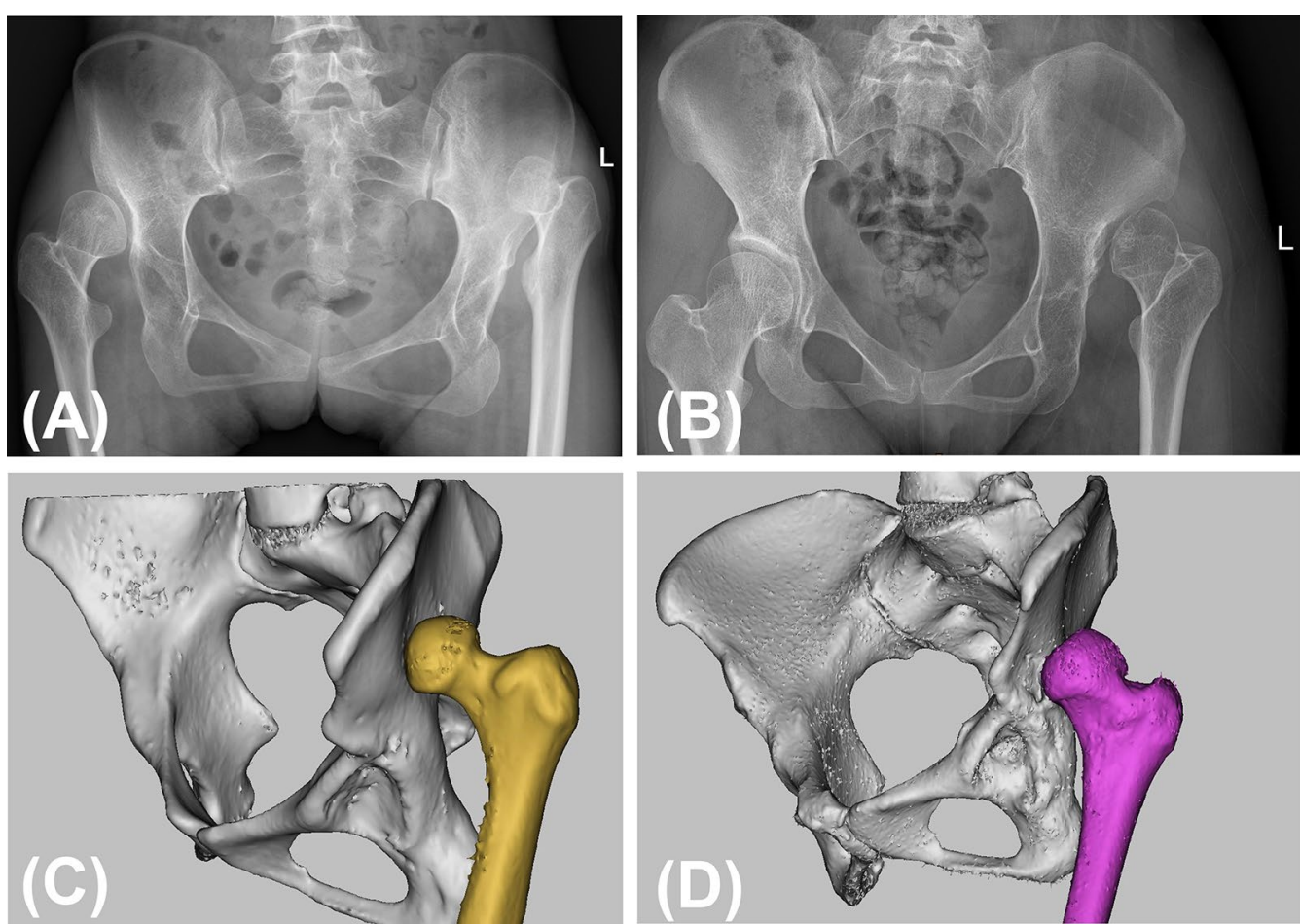

Fig. 1 AP radiograph and 3D model two types of Crowe IV DDH. A, C A 22-year-old female patient in Crowe type IVa group (L: IVa, R: III). B, D A 30-year-old female patient in Crowe type IVb group (L: IVb)

Table 1 Demographic data

\begin{tabular}{|c|c|c|c|c|}
\hline & \multicolumn{2}{|l|}{$\mathrm{DDH}(n=51)$} & \multirow[t]{2}{*}{$p$} & \multirow[t]{2}{*}{ Normal $(n=30)$} \\
\hline & $\begin{array}{l}\text { IVa }(n=25, \text { without false } \\
\text { acetabulum) }\end{array}$ & IVb $(n=26$, with false acetabulum) & & \\
\hline Patient (No.) & 22 & 23 & - & 15 \\
\hline Gender(F/M) & $2 / 20$ & $3 / 20$ & 0.673 & $2 / 13$ \\
\hline Age (y) & $41.91 \pm 15.27(21-70)$ & $43.70 \pm 11.52(23-65)$ & 0.630 & $41.40 \pm 8.04(29-54)$ \\
\hline Height (cm) & $159.32 \pm 11.81(141-179)$ & $156.78 \pm 8.65(143-175)$ & 0.389 & $163.20 \pm 8.04(155-185)$ \\
\hline Weight (kg) & $60.36 \pm 10.69(40-80)$ & $54.91 \pm 12.29(30-84)^{\#}$ & 0.317 & $65.07 \pm 8.55(49-87)$ \\
\hline BMI $\left(\mathrm{kg} / \mathrm{m}^{2}\right)$ & $23.84 \pm 3.91(18.73-30.08)$ & $22.43 \pm 5.25(13.33-35.42)$ & 0.277 & $24.47 \pm 2.97(18.00-29.14$ \\
\hline
\end{tabular}

Values are expressed as the mean and the standard deviation, with range in parentheses; $p$ means the differences between the cortical widths of type IVa DDH and type IVb DDH; ${ }^{p} p<0.05$, when compared with control group

format and imported into Mimics 19.0 software (Materialise, Leuven, Belgium) for 3D reconstruction. Accordingly, the 3D, coronal, sagittal and transverse views were presented simultaneously in Mimics software. First, the center of the femoral head was established based on the fitting sphere of femoral head. Second, the center of the lesser trochanter (CLT) is the most prominent point on the lesser trochanter on the 3D model. The central axis of the femoral medullary canal was defined as the line between the geometric centers of the medullary canal at the level of $20 \mathrm{~mm}$ below the CLT and isthmus of the femur. Thus, the coronal femoral plane was determined by the femoral head center and the central axis of the femoral medullary (Fig. 2A).

Based on the coronal plane, the $3 \mathrm{D}$ model and CT images were reoriented and the following morphological evaluations included (Fig. 2B): (1) Height of the femoral head (FH): the vertical distance between the femoral head center and level of CLT. (2) Height of the greater trochanter (GT): the vertical distance between the tip of the greater trochanter and the level of CLT. (3) GT-FH height discrepancy. (4) Height of the isthmus: the vertical 


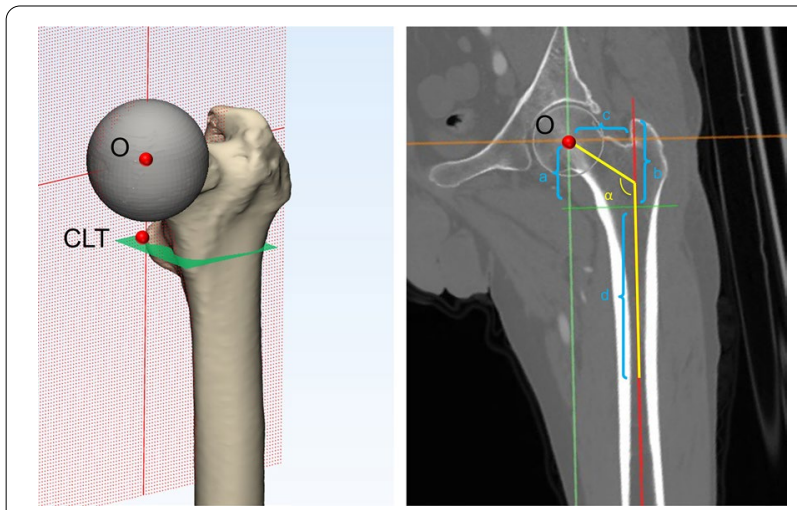

Fig. $23 \mathrm{D}$ model and the coronal femoral plane of the proximal femur of DDH. O: femoral head center; CLT: center of the lesser trochanter; a: height of FH; $b$ : height of GT; c: femoral offset; $d$ : height of isthmus; a: neck-shaft angle; $\mathrm{GT}=$ greater trochanter, $\mathrm{FH}=$ femoral head distance between the level of isthmus and CLT. (5) Neckshaft angle: the femoral neck axis was first defined by connecting the femoral head center and the midpoint of the narrowest part of the femoral neck; the neck-shaft angle was defined as the angle between the femoral neck axis and the central axis of the femoral medullary canal. (6) Femoral offset: the horizontal distance between the femoral head center and the central axis of the femoral medullary canal. (7) Anteversion of the femoral neck: the angle between the post-condylar line and the projection of the femoral neck axis on the axial plane.

Refer to the medullary canal parameters, femoral model was evaluated from the level of $20 \mathrm{~mm}$ above the CLT $\left(\mathrm{C}_{+20}\right)$ to the level of $40 \mathrm{~mm}$ below the CLT $\left(\mathrm{C}_{-40}\right)$ at $10-\mathrm{mm}$ intervals (Fig. 3A). Based on the method described by Noble and Sugano et al. [14, 15], the mediolateral (ML) and anteroposterior (AP) widths of medullary canal were measured. Accordingly, the ML width

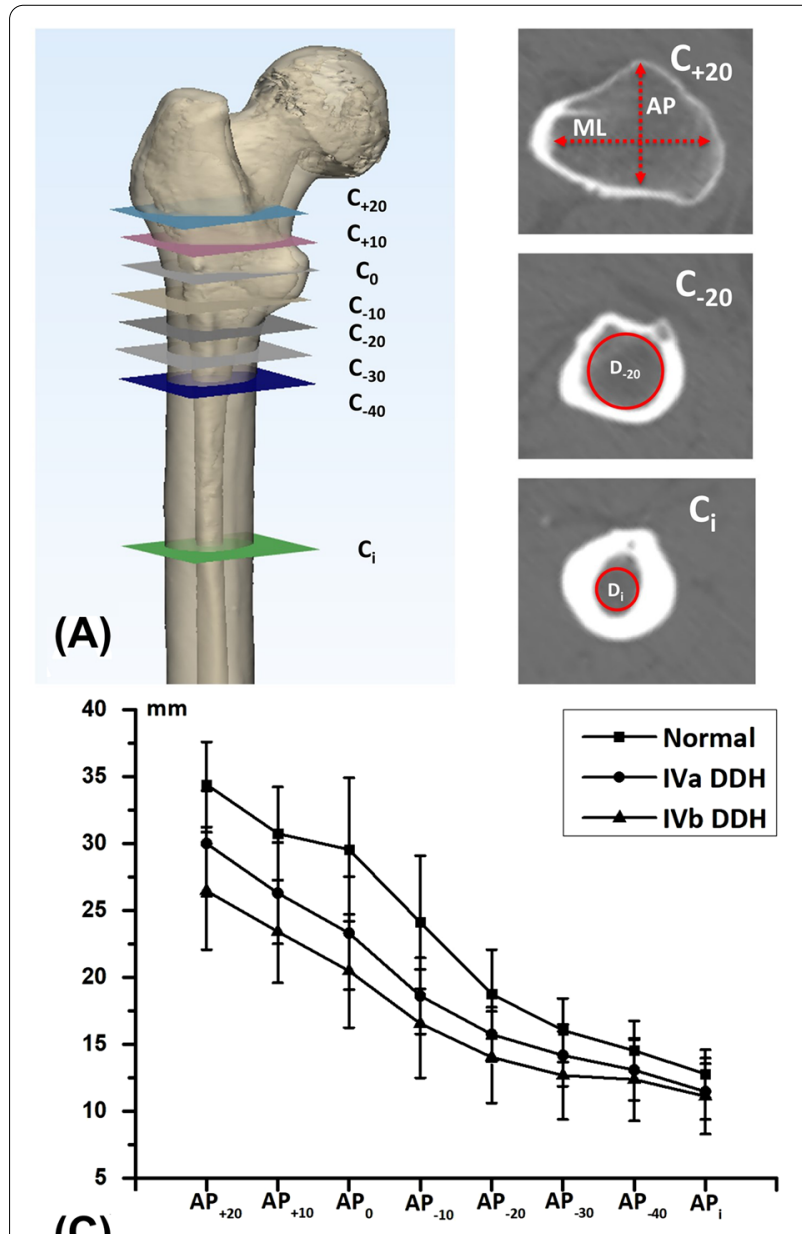

(C)
(B)
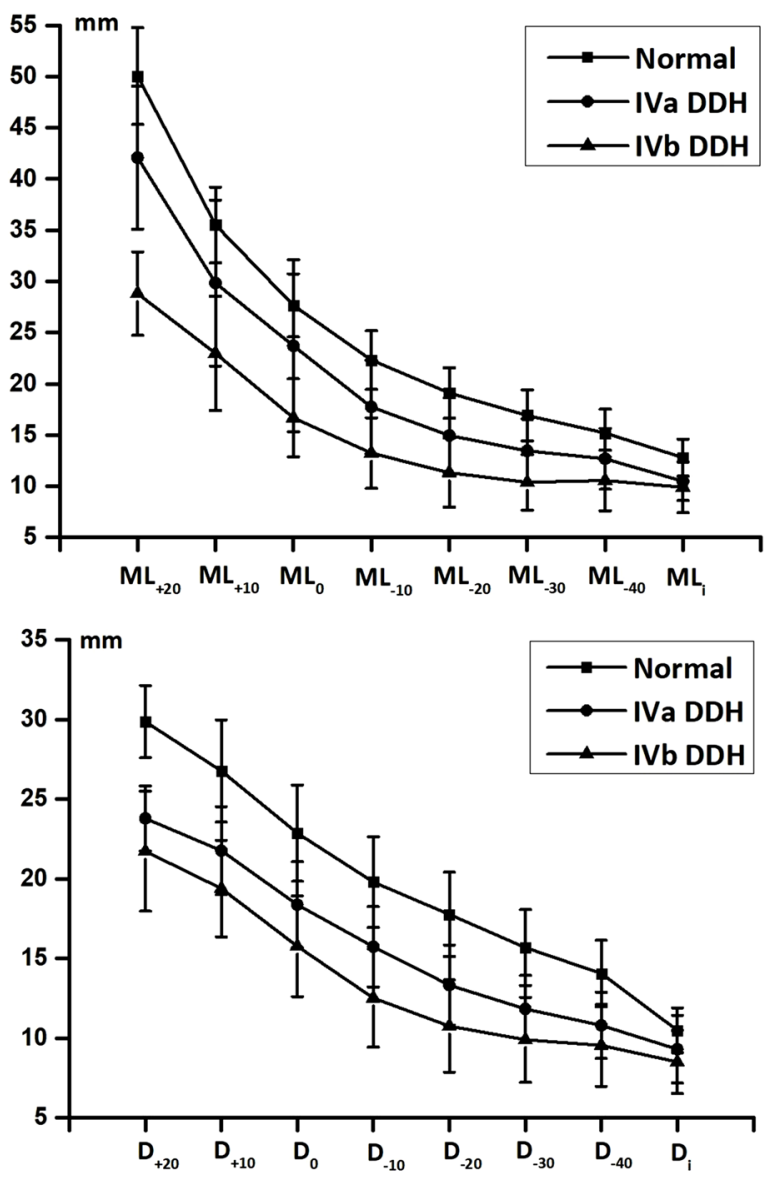

Fig. 3 Measurements of medullary canal dimensional parameters. A Definition of the femoral medullary canal axial sections at 1-cm intervals from $2 \mathrm{~cm}$ above the $\mathrm{CLT}\left(\mathrm{C}_{+20}\right)$ to $4 \mathrm{~cm}$ below the $\mathrm{CLT}\left(\mathrm{C}_{-40}\right)$ and the section of isthmus $\left(\mathrm{C}_{\mathrm{j}}\right)$. Dimensional parameters contain ML canal width, AP canal width and diameter of the best-fitting circle of the medullary canal. B ML canal widths in IVa, IVb and normal groups. C AP canal widths in IVa, IVb and normal groups. D Diameters in IVa, IVb and normal groups 
was measured in planes parallel to the femoral neck axis and the AP width was measured perpendicular to the ML width. Further, a circle was also created to best fill the inner contour of medullary canal [4]. The ML width, AP width and fitting circle diameter of medullary canal were measured to describe the medullary morphology on each axial plane, as well as the level of isthmus. As described previously, canal flare index (CFI) was calculated as the ratio between the widths of the medullary canal at the level of the $20 \mathrm{~mm}$ above the CLT and the isthmus [16]. Metaphyseal canal flare index (MCFI) was calculated as the ratio between the widths of the medullary canal at the levels of $20 \mathrm{~mm}$ above and $20 \mathrm{~mm}$ below the CLT [17]. Diaphyseal canal flare index (DCFI) was calculated as the ratio between the widths of the medullary canal at the level of $20 \mathrm{~mm}$ below the CLT and the isthmus [4].

\section{Statistical analysis}

Kolmogorov-Smirnov tests were performed to determine the distributions of the data. For parametric data, when the variances in groups were same, one-way ANOVA was used to compare the differences among groups, followed by the least significant difference (LSD) method for pairwise comparisons. For nonparametric data or when variances in groups were different, Kruskal-Wallis analysis of variance was performed, followed by Dunn's test for pairwise comparisons. For assessing interobserver reliability, two analysts performed point selection and corresponding measurements independently. For assessing intraobserver reliability, measurements were repeated one month later by the same analysts. The intraclass correlation coefficient was used to calculate interobserver and intraobserver effects. A post hoc power calculation was determined by the statistical power analyses G Power
3.1 to eliminate type II error [18]. All statistical analyses were performed using SPSS version 21.0 (SPSS, Chicago, IL, USA), and a $p$ value $<0.05$ was considered statistically significant.

\section{Results}

The anatomy of the dysplastic femur and corresponding bony structures were evaluated following 3D reconstruction. As listed in Table 1, patients in IVa, IVb and normal groups had a comparable mean age and body mass index (BMI). Intraclass correlation coefficient results of the intraobserver and interobserver reliabilities for all the measurement indices, evaluated by the one-way randomeffects model, ranged from 0.93 to 0.97 and from 0.82 to 0.93 , respectively. Post hoc power analysis showed a power $>0.84$ for detecting a significant difference.

According to the measurements of standard AP plain radiographs, both the dislocation height and dislocation rate were significantly higher in the IVa DDH group $(65.34 \pm 9.83 \mathrm{~mm})$ than in the IVb DDH group $(52.24 \pm 11.42 \mathrm{~mm})$. Compared with the normal femurs, the dislocated femurs had a higher femoral head, larger GT-FH height discrepancy between, larger femoral neck anteversion and smaller femoral offset. Moreover, the position of the femoral isthmus was significantly higher in the DDH groups. Further, the IVb DDH had a significantly lower isthmus position, larger neck-shaft angle and smaller femoral neck anteversion than that in IVa $\mathrm{DDH}$. There was no significant difference in the position of FH and GT and femoral offset between DDH groups (Table 2).

Regarding the morphology of medullary canal (Fig. 3B), the ML, AP canal widths and the diameter of medullary canal in both DDH groups were significantly smaller than

Table 2 Parameters of proximal femoral anatomy for DDH and control groups

\begin{tabular}{|c|c|c|c|c|}
\hline & \multicolumn{2}{|l|}{$\mathrm{DDH}(n=51)$} & \multirow[t]{2}{*}{$p$} & \multirow[t]{2}{*}{ Normal $(n=30)$} \\
\hline & $\begin{array}{l}\text { IVa } \\
(n=25, \text { without false acetabulum) }\end{array}$ & $\begin{array}{l}\text { IVb } \\
(n=26, \text { with false acetabulum) }\end{array}$ & & \\
\hline Height of the dislocation (mm) & $65.34 \pm 9.83(46.79-81.35)$ & $52.24 \pm 11.42(39.18-76.91)$ & $0.000^{* *}$ & / \\
\hline Dislocation rate (\%) & $31.88 \pm 4.10(24.52-38.62)$ & $24.99 \pm 4.81(20.08-36.30)$ & $0.000^{* *}$ & / \\
\hline Height of the FH (mm) & $38.99 \pm 7.81(23.12-53.19)^{\# \#}$ & $37.35 \pm 6.48(19.80-47.41)^{\# \#}$ & 0.395 & $45.55 \pm 6.25(34.53-64.37)$ \\
\hline Height of the GT (mm) & $54.72 \pm 4.90(46.27-64.24)$ & $51.87 \pm 4.72(44.57-61.91)^{\# \#}$ & 0.052 & $55.88 \pm 5.71(47.08-71.13)$ \\
\hline GT-FH height discrepancy (mm) & $15.73 \pm 5.13(6.90-29.69)^{\# \#}$ & $14.52 \pm 5.42(1.92-27.65)^{\# \#}$ & 0.356 & $10.34 \pm 3.37(4.25-16.81)$ \\
\hline Height of the isthmus (mm) & $68.16 \pm 26.87(25.18-128.02)^{\# \#}$ & $87.93 \pm 23.71(35.63-125.23)^{\# \#}$ & $0.023^{*}$ & $114.10 \pm 15.82(82.28-147.91)$ \\
\hline Femoral offset (mm) & $31.41 \pm 7.27(16.51-46.80)^{\# \#}$ & $33.90 \pm 3.72(27.02-42.29)^{\# \#}$ & 0.345 & $41.38 \pm 3.28(34.78-49.40)$ \\
\hline Neck-shaft angle $\left(^{\circ}\right)$ & $114.64 \pm 7.58(97.79-127.65)^{\# \#}$ & $126.51 \pm 7.58(113.62-143.87)$ & $0.000^{* *}$ & $125.44 \pm 4.72(117.99-136.16)$ \\
\hline Femoral neck anteversion $\left({ }^{\circ}\right)$ & $41.35 \pm 14.55(3.26-65.19)^{\# \#}$ & $25.94 \pm 11.06(4.13-51.63)^{\# \#}$ & $0.000^{* *}$ & $14.96 \pm 9.03(2.40-35.84)$ \\
\hline
\end{tabular}

Values are presented as the mean and the standard deviation, with range in parentheses; $p$ means the differences between the cortical widths of type IVa DDH and type IVb DDH; ${ }^{*} p<0.05,{ }^{* *} p<0.01$ for the comparison between the DDH groups; ${ }^{\#} p<0.05,{ }^{\# \#} p<0.01$, when compared with control group

GT greater trochanter, $\mathrm{FH}$ femoral head 


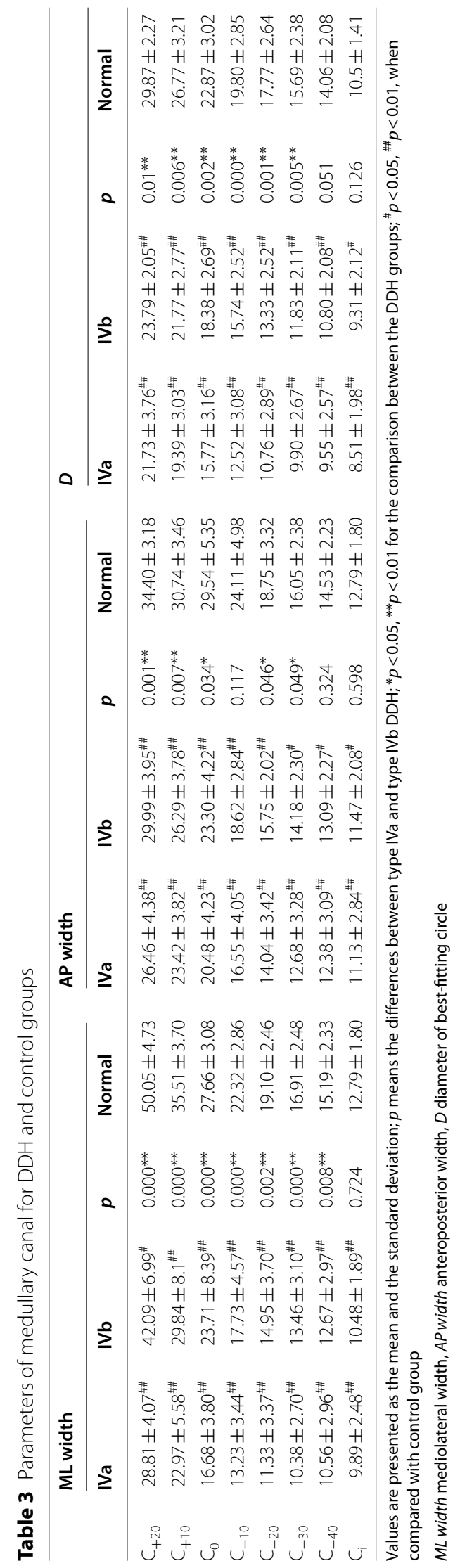


normal group from $\mathrm{C}_{+20}$ to $\mathrm{C}_{-40}$ and at the level of isthmus. Within DDH groups, the AP width and diameter of the IVa femurs were smaller than the IVb femurs from $\mathrm{C}_{20}$ to $\mathrm{C}_{-30}$, similar to $\mathrm{ML}$ width from $\mathrm{C}_{+20}$ to $\mathrm{C}_{-40}$, while there was no significant difference in anatomic measurements at the level of isthmus between IVa and IVb groups (Table 3). As detailed in Table 4, ML-CFI and $\mathrm{D}_{+20} / \mathrm{Di}$ of DDH femurs were smaller than normal femurs. Further, IVa femurs appeared to be more stovepipe-like than IVb femurs in the ML dimension $(3.02 \pm 0.53 \mathrm{~mm}$ vs. $3.99 \pm 0.71 \mathrm{~mm}, p=0.000)$. However, there was no difference of $\mathrm{D}_{+20} / \mathrm{Di}$ between IVa and IVb femurs. According to the metaphyseal canal, there was no statistical difference of MCFI between DDH and normal femurs in both ML and AP dimensions. While IVa femurs had a larger $\mathrm{D}_{+20} / \mathrm{D}_{-20}$ than IVb and normal femurs. According to the diaphyseal canal, all the quantitative ratios of DDH femurs were smaller than normal femurs, except for IVb femurs in the AP dimension. Moreover, ML-DCFI, AP$\mathrm{DCFI}$ and $\mathrm{D}_{-20} / \mathrm{Di}$ of IVb femurs were significantly larger than IVa femurs.

\section{Discussion}

Although femoral reconstruction in patients with Crowe IV DDH shows reliable advantages and clinical outcomes, the complications including intraoperative fracture [19, $20]$ and nonunion at the osteotomy site [21-23] still rate from 5 to $25 \%$. The anatomical deformities presented in the proximal femur in patients with high dislocation are recognized as major surgical challenges [24, 25]. Therefore, in the present study, we evaluated the 3D-CT-based morphological analysis of proximal femoral anatomy and medullary canal in hips affected by Crowe IV DDH. According to the absence or presence of false acetabulum, we also found a series of anatomical distinctions between IVa and IVb femurs.

Commonly, the dysplastic femur was described in terms of greater anteversion, larger valgus deformity and narrower intramedullary canal $[14,26]$. However, we found neck-shaft angle in the Crowe IVa group was significantly smaller than that of IVb and normal group, whereas no difference was found between IVb and normal groups. Our results were consistent with the conclusion of Liu [4] and Wang et al. [27], but $\mathrm{Du}$ reported that the angle in IVb was larger than the contralateral normal femur [10]. The medial offset in both DDH groups was smaller than the normal group and no difference was found between DDH groups, which was consistent with results of $\mathrm{Du}[10]$ and Noble et al. [15]. Similarly, we found both DDH femurs had a smaller distance between lesser trochanter and isthmus than normal femurs [4]. Regarding the femoral neck anteversion, dysplastic femurs had a significantly larger anteversion than the normal femurs. Without the restriction of false acetabulum, the IVa femurs had a notably larger anteversion than IVb femurs, which was different from the comparable results previously [27]. Compared with the normal femur, both IVa and IVb femurs had smaller head height and IVb femurs had larger greater trochanter height, resulting in larger GT$\mathrm{FH}$ height discrepancy in both DDH groups. By contrast, there was no difference in the height of GT and FH between the DDH groups.

From the observations in this study, false acetabulum plays an important role in load transmission and bone remodeling. First, the presence of false acetabulum restrained the excessive dislocation of the affected femur, resulting in significantly smaller dislocation height in IVb group. Second, the isthmus position was more proximal in IVa than IVb femurs.

Together with the excessively narrow medullary canal, surgeons should pay close attention to avoid periprosthetic femoral fractures during femoral reconstruction. Third, IVa femurs had a significantly smaller neck-shaft angle and larger neck anteversion. It has been reported that the load transfer during the developing period was associated with a longer femoral neck and higher neckshaft angle [28]. Thus, the abnormal morphology in IV femurs potentially compromising the component fixation and THA results should be adequately considered preoperatively.

Regarding the internal dimensions of the femoral canal, Argenson [3, 5] and Noble et al. [15] have conducted a series of CT-based studies and revealed the parameters were comparable for all groups of dysplastic hips and smaller than those of the control group. However, there were only a small number of patients with high dislocation, and they did not perform the subgroup analysis. In the present study, the ML, AP widths and diameter in both DDH groups were significantly smaller than those of the control group from $\mathrm{C}_{+20}$ to $\mathrm{C}_{-40}$ and at the level of isthmus. Meanwhile, the medullary canal of the Crowe IVa was narrower than IVb in almost all the sections, except for the isthmus level. Du et al. [10] also reported similar results that there was no significant dimensional difference at the level of isthmus. However, Wang et al. [27] demonstrated that the dimensional widths of femurs without false acetabulum were narrower in all the sections. In normal femurs, the ML width of proximal femoral canal is always longer than the AP width [17]. However, the ML width of IVb femurs became smaller than AP width from the $\mathrm{C}_{-10}$ level, and the abnormal condition of IVa femurs began from the $\mathrm{C}_{+10}$ level. Similar as reported previously [29-31], the abnormal bony 
Table 4 Canal flare indices for DDH and control groups

\begin{tabular}{|c|c|c|c|c|}
\hline & \multicolumn{2}{|l|}{$\mathrm{DDH}(n=51)$} & \multirow[t]{2}{*}{$p$} & \multirow[t]{2}{*}{ Normal $(n=30)$} \\
\hline & IVa $(n=25)$ & $\mathrm{IVb}(n=26)$ & & \\
\hline ML-CFI & $3.02 \pm 0.53^{\# \#}$ & $3.99 \pm 0.71^{\#}$ & $0.000^{* *}$ & $4.39 \pm 0.40$ \\
\hline AP-CFI & $2.47 \pm 0.54$ & $2.74 \pm 0.65$ & 0.079 & $2.70 \pm 0.40$ \\
\hline $\mathrm{D}_{+20} / \mathrm{Di}$ & $2.61 \pm 0.43^{\#}$ & $2.53 \pm 0.47^{\# \#}$ & 0.500 & $2.89 \pm 0.41$ \\
\hline ML-MCFI & $2.68 \pm 0.56$ & $2.86 \pm 0.55$ & 0.599 & $2.65 \pm 0.31$ \\
\hline AP-MCFI & $1.96 \pm 0.45$ & $1.96 \pm 0.33$ & 0.999 & $1.86 \pm 0.27$ \\
\hline $\mathrm{D}_{+20} / \mathrm{D}_{-20}$ & $2.10 \pm 0.42^{\#}$ & $1.83 \pm 0.28$ & $0.014^{*}$ & $1.82 \pm 0.43$ \\
\hline ML-DCFI & $1.14 \pm 0.13^{\# \#}$ & $1.42 \pm 0.22^{\# \#}$ & $0.000^{* *}$ & $1.68 \pm 0.21$ \\
\hline AP-DCFI & $1.27 \pm 0.18^{\# \#}$ & $1.39 \pm 0.18$ & $0.037^{*}$ & $1.47 \pm 0.23$ \\
\hline $\mathrm{D}_{-20} / \mathrm{Di}$ & $1.26 \pm 0.16^{\# \#}$ & $1.42 \pm 0.20^{\# \#}$ & $0.005^{* *}$ & $1.70 \pm 0.21$ \\
\hline
\end{tabular}

Values are presented as the mean and the standard deviation; $p$ means the differences between type IVa and type IVb DDH; ${ }^{*} p<0.05,{ }^{* *} p<0.01$ for the comparison between the DDH groups; ${ }^{\#} p<0.05,{ }^{\# \#} p<0.01$, when compared with control group

CFI canal flare index, MCFI metaphyseal canal flare index, DCFI diaphyseal canal flare index

torsion existed through the entire lower limb in dysplastic hips.

In the setting of high dislocation hip, the S-ROM cementless femoral stem (DePuy, Warsaw, USA) is widely used to achieve a better fit and fill in both the metaphyseal and diaphyseal medullary canal and can also adjust the excessive anteversion [32-34]. Considering the cylindrical shape of the S-ROM distal stem, we chose the best-fitting circle to evaluate the medullary canal quantitatively instead of ML and AP canal widths. To avoid the periprosthetic femoral fractures, the diameter of fitting circle makes more sense than the longest canal width, which can also eliminate the influence of rotational deformity [4]. In the present study, we found that diameters in both $\mathrm{DDH}$ groups were significantly smaller than that in the normal group from $\mathrm{C}_{20}$ to $\mathrm{C}_{-40}$ and at the level of isthmus. The diameters of IVa femurs were smaller than IVb femurs from $\mathrm{C}_{+20}$ to $\mathrm{C}_{-30}$. Moreover, the dimensional discrepancies of diameters with the normal group at each level were notably reduced, especially compared with ML canal widths. Theoretically, we believed that the diameter parameter might have important clinical relevance for oriented prosthesis design of the DDH femoral stem.

For depicting the characteristic of the medullary canal of Crowe IV DDH, the proximal femur was divided into metaphyseal, diaphyseal and overall three regions. In the metaphyseal region, all the dimensional indices of IVb were comparable with normal femurs. However, the $\mathrm{D}_{+20} / \mathrm{D}_{-20}$ of IVa group was larger than that of $\mathrm{IVb}$ group. In the diaphyseal region, all indices in DDH groups were smaller and IVa femurs were more stovepipe-like than IVb femurs in all the dimensions. Totally,
CFIs were smaller in DDH femurs in the ML but not the AP dimension. Further, the index of IVa femur was smaller than IVb only in the ML dimension but comparable in $\mathrm{D}_{+20} / \mathrm{Di}$. Similarly, Wang et al. [27] also reported that femurs without false acetabulum had a lower CFI in the ML dimension but not the AP dimension. Under the stress of false acetabulum, medullary deformity of IVb femur mainly occurred in the diaphyseal region. By contrast, the medullary deformity occurred in the whole IVa proximal femur.

When performing the femoral reconstruction in THA, intraoperative periprosthetic fracture is proved to be associated with the abnormal morphology of femoral medullary canal $[7,35]$. First, all dimensional parameters of Crowe IV femurs were significantly narrower in both metaphyseal and diaphyseal regions. In this regard, the modular femoral stem can offer both regional implant size and effectively segmental fixation. Second, medullary canal of IVa femurs was notably narrower and more dysplastic in the metaphyseal region. As reported [36], most intraoperative periprosthetic femoral fractures were classified as Vancouver Type A and Type B. The application of prophylactic cerclage wire in the metaphyseal region before the proximal cone reaming may effectively avoid relative complications. Last, 3D reconstruction and quantitative analysis in the present study can offer accurate anatomic information of dysplastic femurs. Accordingly, comprehensive preoperative planning is essential for implant prediction and complication avoidance.

The limitations of our study should be noted. First, the sample size was relatively small. However, the Crowe IV hips are uncommon and the results of statistical analysis indicated reliable reproducibility. Further study needs to be done to recruit more high dislocated patients to make the results more conclusive. Second, our study only focused on the morphological features of the proximal femur without results of the corresponding clinical complications and implant survival. Further combined studies will provide more valuable clinical guidance.

\section{Conclusions}

High dislocated femurs are associated with more anteverted femoral neck, smaller femoral offset and narrower medullary canal. Without stimulation of the false acetabulum, IVa femurs were associated with higher dislocation and notably narrower medullary canal, whose variation of medullary canal located in the whole proximal femur. The 3D quantitative analysis in our study may have important clinical relevance for surgeons who perform femoral reconstruction in Crowe type IV hips. 


\section{Abbreviations}

DDH: Developmental dysplasia of the hip; THA: Total hip arthroplasty; 2/3D: Two-/three-dimensional; FH: Femoral head; GT: Greater trochanter; ML width: Mediolateral (ML) width; AP width: Anterolateral (AP) width; CFI: Canal flare index; MCFI: Metaphyseal canal flare index; DCFI: Diaphyseal canal flare index.

\section{Acknowledgements}

Not applicable.

\section{Authors' contributions}

YHY, WHL and QJZ performed study design. YHY and WHL done 3D reconstruction and measurement performance. WQY, HJ and GTF collected the data. YCM done data analysis and data interpretation. YHY drafted the manuscript. QJZ and YCM approved the final version of manuscript. QJZ takes responsibility for the integrity of the data analysis. All authors read and approved the final manuscript.

\section{Funding}

This study was supported by Technological Research Fund of Guangdong Provincial People's Hospital (2018bq11), Medical Science and Technology Research Fund of Guangdong Province (A2020026), and Program of Science and Technology of Guangzhou (202102020959).

\section{Availability of data and materials}

All the data used and/or analyzed during this study are available upon reasonable request from the corresponding author.

\section{Declarations}

\section{Ethics approval and consent to participate}

This study was approved by the institutional review board of Guangdong Provincial People's Hospital (IRB: 2019528HR1). All methods were carried out in accordance with relevant guidelines and regulations. Informed consent was obtained in writing from all the individual participants included in the study.

\section{Consent for publication}

Written informed consent was obtained from all patients for publication of this study and any accompanying images.

\section{Competing interests}

The authors declare that they have no competing interests.

\section{Author details}

${ }^{1}$ Department of Orthopedics, Guangdong Provincial People's Hospital, Guangdong Academy of Medical Sciences, 106, Zhongshan Second Road, Yuexiu District, Guangzhou 510080, Guangdong Province, People's Republic of China. ${ }^{2}$ Department of Operating Room, Guangdong Provincial People's Hospital, Guangdong Academy of Medical Sciences, 106, Zhongshan Second Road, Yuexiu District, Guangzhou 510080, People's Republic of China.

Received: 31 August 2021 Accepted: 11 October 2021 Published online: 18 October 2021

\section{References}

1. Hartofilakidis G, Stamos K, Karachalios T, Ioannidis TT, Zacharakis N. Congenital hip disease in adults. Classification of acetabular deficiencies and operative treatment with acetabuloplasty combined with total hip arthroplasty. J Bone Joint Surg Am. 1996;78(5):683-92.

2. Karachalios T, Hartofilakidis G. Congenital hip disease in adults: terminology, classification, pre-operative planning and management. J Bone Joint Surg Br. 2010;92(7):914-21.

3. Argenson J-NA, Flecher $X$, Parratte $S$, Aubaniac J-M. PRESIDENTIAL GUEST LECTURE: anatomy of the dysplastic hip and consequences for total hip arthroplasty. Clin Orthop Relat Res. 2007;465:40-5.

4. Liu S, Zuo J, Li Z, Yang Y, Liu T, Xiao J, et al. Study of three-dimensional morphology of the proximal femur in developmental adult dysplasia of the hip suggests that the on-shelf modular prosthesis may not be an ideal choice for patients with Crowe type IV hips. International orthopaedics. 2016.

5. Argenson J-N, Ryembault E, Flecher X, Brassart N, Parratte S, Aubaniac J-M. Three-dimensional anatomy of the hip in osteoarthritis after developmental dysplasia. Bone Joint J. 2005;87(9):1192-6.

6. Hartofilakidis G, Babis GC, Lampropoulou-Adamidou K, Vlamis J. Results of total hip arthroplasty differ in subtypes of high dislocation. Clin Orthop Relat Res. 2013;471(9):2972-9.

7. Liu B, Liu SK, Wu T, Liu ZM, Chen X, Li MN, et al. Risk factors for intraoperative periprosthetic femoral fractures in patients with hip dysplasia undergoing total hip arthroplasty with uncemented prostheses. Orthop Surg. 2021

8. Ding ZC, Zeng WN, Mou P, Liang ZM, Wang D, Zhou ZK. Risk of dislocation after total hip arthroplasty in patients with crowe type IV developmental dysplasia of the hip. Orthop Surg. 2020;12(2):589-600.

9. Ma H, Zhou Y, Zheng C, Cao W, Du Y. New classification of Crowe type IV developmental dysplasia of the hip. China J Orthop Traumatol. 2016;29(2):119.

10. Du Y, Li T, Sun J, Ni M, Zhou Y. The effect of the false acetabulum on femoral proximal medullary canal in unilateral Crowe type IV developmental dislocation of the hip. Ther Clin Risk Manag. 2020;16:631-7.

11. Peng $H$, Zhang G, Xu C, Wang T, Wang Y. Is pseudoacetabulum an important factor determining SSTO application in total hip arthroplasty for Crowe IV hips? A retrospective cohort study. J Orthop Surg Res. 2019;14(1):201

12. Xu H, Zhou Y, Liu Q, Tang Q, Yin J. Femoral morphologic differences in subtypes of high developmental dislocation of the hip. Clin Orthop Relat Res. 2010;468(12):3371-6.

13. Yang Y, Zuo J, Liu T, Xiao J, Liu S, Gao Z. Morphological analysis of true acetabulum in hip dysplasia (Crowe Classes I-IV) via 3-D implantation simulation. J Bone Joint Sur Am. 2017;99(17):e92.

14. Sugano N, Noble PC, Kamaric E, Salama JK, Ochi T, Tullos HS. The morphology of the femur in developmental dysplasia of the hip. Journal Bone Joint Surg Brit Vol. 1998;80(4):711-9.

15. Noble PC, Kamaric E, Sugano N, Matsubara M, Harada Y, Ohzono K, et al. Three-dimensional shape of the dysplastic femur: implications for THR. Clin Orthop Relat Res. 2003;417:27-40.

16. Noble PC, Alexander JW, Lindahl LJ, Yew DT, Granberry WM, Tullos HS The anatomic basis of femoral component design. Clin Orthop Relat Res. 1988;235:148-65.

17. Laine HJ, Lehto MU, Moilanen T. Diversity of proximal femoral medullary canal. J Arthroplasty. 2000;15(1):86-92.

18. Faul F, Erdfelder E, Lang A-G, Buchner A. G* Power 3: a flexible statistical power analysis program for the social, behavioral, and biomedical sciences. Behav Res Methods. 2007;39(2):175-91.

19. Masonis JL, Patel JV, Miu A, Bourne RB, McCalden R, Macdonald SJ, et al. Subtrochanteric shortening and derotational osteotomy in primary total hip arthroplasty for patients with severe hip dysplasia: 5-year follow-up. J Arthroplasty. 2003;18(3 Suppl 1):68-73.

20. Togrul E, Ozkan C, Kalaci A, Gülşen M. A new technique of subtrochanteric shortening in total hip replacement for Crowe type 3 to 4 dysplasia of the hip. J Arthroplasty. 2010;25(3):465-70.

21. Bruce WJ, Rizkallah SM, Kwon YM, Goldberg JA, Walsh WR. A new technique of subtrochanteric shortening in total hip arthroplasty: surgical technique and results of 9 cases. J Arthroplasty. 2000;15(5):617-26.

22. Biant LC, Bruce WJ, Assini JB, Walker PM, Walsh WR. Primary total hip arthroplasty in severe developmental dysplasia of the hip. Ten-year results using a cementless modular stem. J Arthroplasty. 2009;24(1):27-32.

23. Wang D, Li DH, Li Q, Wang HY, Luo ZY, Yang Y, et al. Subtrochanteric shortening osteotomy during cementless total hip arthroplasty in young patients with severe developmental dysplasia of the hip. BMC Musculoskelet Disord. 2017;18(1):491.

24. Weinstein SL, Dolan LA. Proximal femoral growth disturbance in developmental dysplasia of the hip: What do we know? J Child Orthop. 2018;12(4):331-41.

25. Greber EM, Pelt CE, Gililland JM, Anderson MB, Erickson JA, Peters CL. Challenges in total hip arthroplasty in the setting of developmental dysplasia of the hip. J Arthroplasty. 2017;32(9s):S38-s44. 
26. Shefelbine SJ, Carter DR. Mechanobiological predictions of growth front morphology in developmental hip dysplasia. J Orthop Res Off Publ Orthop Res Soc. 2004;22(2):346-52.

27. Wang Z, Li H, Zhou Y, Deng W. Three-dimensional femoral morphology in Hartofilakidis type $C$ developmental dysplastic hips and the implications for total hip arthroplasty. Int Orthop. 2020;44(10):1935-42.

28. Ireland A, Saunders FR, Muthuri SG, Pavlova AV, Hardy RJ, Martin KR, et al. Age at onset of walking in infancy is associated with hip shape in early old age. J Bone Miner Res Off J Am Soc Bone Miner Res. 2019;34(3):455-63.

29. Cho KJ, Park KS, Shin YR, Yang HY, Yoon TR. Relationship between femoral anteversion and tibial torsion: CT evaluation of 38 unilateral developmental dysplasia of the hip patients. Hip Int J Clin Exp Res Hip Pathol Ther. 2018;28(5):548-53.

30. Han Q, Zhang A, Wang C, Yang K, Wang J. Application of threedimensional reconstruction to improve the preoperative measurement accuracy and applicability of femoral neck torsion angle. Medicine. 2019;98(45):e17727.

31. Zhang M, Liu BL, Qi XZ, Yang QQ, Sun JY, Zheng QY, et al. The threedimensional morphology of femoral medullary cavity in the developmental dysplasia of the hip. Front Bioeng Biotechnol. 2021;9:684832.

32. Ueoka K, Kabata T, Kajino Y, Inoue D, Ohmori T, Ueno T, et al. Patientreported outcomes following primary total hip arthroplasty in Crowe type III or IV developmental dysplasia are comparable to those in Crowe type I: a case-control study of 96 hips with intermediate-term follow-up. BMC Musculoskelet Disord. 2020;21(1):344.

33. Sun C, Zhang Y, Li LT, Ding H, Guo T, Zhao JN. Long-term outcomes of total hip arthroplasty with transverse subtrochanteric shortening osteotomy and modular stem in Crowe IV Developmental dysplasia. J Arthroplasty. 2021;36(2):630-5.

34. Liu T, Yang Y, Shen X, Xiao J, Zuo J, Gao Z. Comparison of two different on-shelf femoral stems for Crowe type IV developmental dysplasia of the hip. J Int Med Res. 2020;48(8):300060520947888.

35. Liu B, Ma W, Li H, Wu T, Huo J, Han Y. Incidence, classification, and risk factors for intraoperative periprosthetic femoral fractures in patients undergoing total hip arthroplasty with a single stem: a retrospective study. J Arthroplasty. 2019;34(7):1400-11.

36. Li M, Hu Y, Xie J. Analysis of the complications of the collum femoris preserving (CFP) prostheses. Acta Orthop Traumatol Turc. 2014;48(6):623-7.

\section{Publisher's Note}

Springer Nature remains neutral with regard to jurisdictional claims in published maps and institutional affiliations.
Ready to submit your research? Choose BMC and benefit from:

- fast, convenient online submission

- thorough peer review by experienced researchers in your field

- rapid publication on acceptance

- support for research data, including large and complex data types

- gold Open Access which fosters wider collaboration and increased citations

- maximum visibility for your research: over $100 \mathrm{M}$ website views per year

At BMC, research is always in progress.

Learn more biomedcentral.com/submissions 